\title{
Functional investigation of methanol dehydrogenase-like protein XoxF in Methylobacterium extorquens AM1
}

\author{
Correspondence \\ Julia A. Vorholt \\ vorholt@micro.biol.ethz.ch
}

Received 27 January 2010

Revised 29 April 2010

Accepted 4 May 2010

\author{
Sabrina Schmidt, Philipp Christen, Patrick Kiefer and Julia A. Vorholt
}

Institute of Microbiology, ETH Zurich, Wolfgang-Pauli-Strasse 10, 8093 Zurich, Switzerland

\begin{abstract}
Methanol dehydrogenase-like protein XoxF of Methylobacterium extorquens AM1 exhibits a sequence identity of $50 \%$ to the catalytic subunit MxaF of periplasmic methanol dehydrogenase in the same organism. The latter has been characterized in detail, identified as a pyrroloquinoline quinone (PQQ)-dependent protein, and shown to be essential for growth in the presence of methanol in this methylotrophic model bacterium. In contrast, the function of XoxF in $M$. extorquens AM1 has not yet been elucidated, and a phenotype remained to be described for a $x O x F$ mutant. Here, we found that a $x o x F$ mutant is less competitive than the wild-type during colonization of the phyllosphere of Arabidopsis thaliana, indicating a function for XoxF during plant colonization. A comparison of the growth parameters of the $M$. extorquens AM1 xoxF mutant with those of the wild-type during exponential growth revealed a reduced methanol uptake rate and a reduced growth rate for the $x o x F$ mutant of about $30 \%$. Experiments with cells starved for carbon revealed that methanol oxidation in the $x o x F$ mutant occurs less rapidly compared with the wildtype, especially in the first minutes after methanol addition. A distinct phenotype for the $x o x F$ mutant was also observed when formate and $\mathrm{CO}_{2}$ production were measured after the addition of methanol or formaldehyde to starved cells. The wild-type, but not the xoxF mutant, accumulated formate upon substrate addition and had a $1 \mathrm{~h}$ lag in $\mathrm{CO}_{2}$ production under the experimental conditions. Determination of the kinetic properties of the purified enzyme showed a conversion capacity for both formaldehyde and methanol. The results suggest that XoxF is involved in onecarbon metabolism in M. extorquens AM1.
\end{abstract}

\section{INTRODUCTION}

Methylotrophy is the ability of organisms to use reduced organic compounds without carbon-carbon bonds, such as methane, methanol and methylamine, as their sole sources of carbon and energy. Among these organisms are members of the genus Methylobacterium, which are aerobic facultative methylotrophic Alphaproteobacteria. They are well-known ubiquitous plant epiphytes and have been described by cultivation-dependent (Corpe \& Rheem, 1989; Hirano \& Upper, 1991; Madhaiyan et al., 2009) as well as cultivation-independent methods (Delmotte et al., 2009; Knief et al., 2008, 2010). Methylobacterium has been

\footnotetext{
Abbreviations: DCPIP, 2,6-dichlorophenol-indophenol; DO, dissolved oxygen; GC-FID, GC-flame ionization detection; PES, phenazine ethosulfate; PQQ, pyrroloquinoline quinone.

Three supplementary figures, showing an amino acid sequence alignment of MxaF and XoxF from $M$. extorquens AM1 without the predicted $\mathrm{N}$-terminal signal peptides, the response of $M$. extorquens AM1 and the xoxF::kan/pCM80 mutant to addition of methanol after carbon starvation, and chromatographic separation and a calibration curve of standard proteins including XoxF on a Superdex 200 column, are available with the online version of this paper.
}

shown to benefit from its ability to use methanol as a substrate, which is advantageous because the one-carbon compound is produced by plants as a by-product of cell wall synthesis (Abanda-Nkpwatt et al., 2006; Fall \& Benson, 1996; Sy et al., 2005). The methylotrophic metabolism of Methylobacterium has been elucidated over the past 50 years. Detailing of the metabolic processes began after the isolation of strain Methylobacterium extorquens AM1 (Peel \& Quayle, 1961), which became an important model to investigate methylotrophy (Chistoserdova et al., 2003; Schrader et al., 2009). When grown in the presence of methanol, the one-carbon substrate is first oxidized to formaldehyde by the periplasmic methanol dehydrogenase (Fig. 1), which is essential for growth in the presence of methanol (Nunn \& Lidstrom, 1986a, b). Methanol dehydrogenase has been shown to be a heterotetrameric enzyme $\left(\alpha_{2} \beta_{2}\right)$ and contains $\mathrm{Ca}^{2+}$ and pyrroloquinoline quinone (PQQ) as a prosthetic group (Afolabi et al., 2001; Anthony \& Zatman, 1964; Williams et al., 2005). The two subunits are encoded by the mxaFI genes found in the large $m x a$ gene cluster, which also encompasses the gene $(m x a G)$ for the natural electron acceptor, a cytochrome $c_{\mathrm{L}}$, as well as genes for enzymes of unknown functions, such as $m x a J$, 


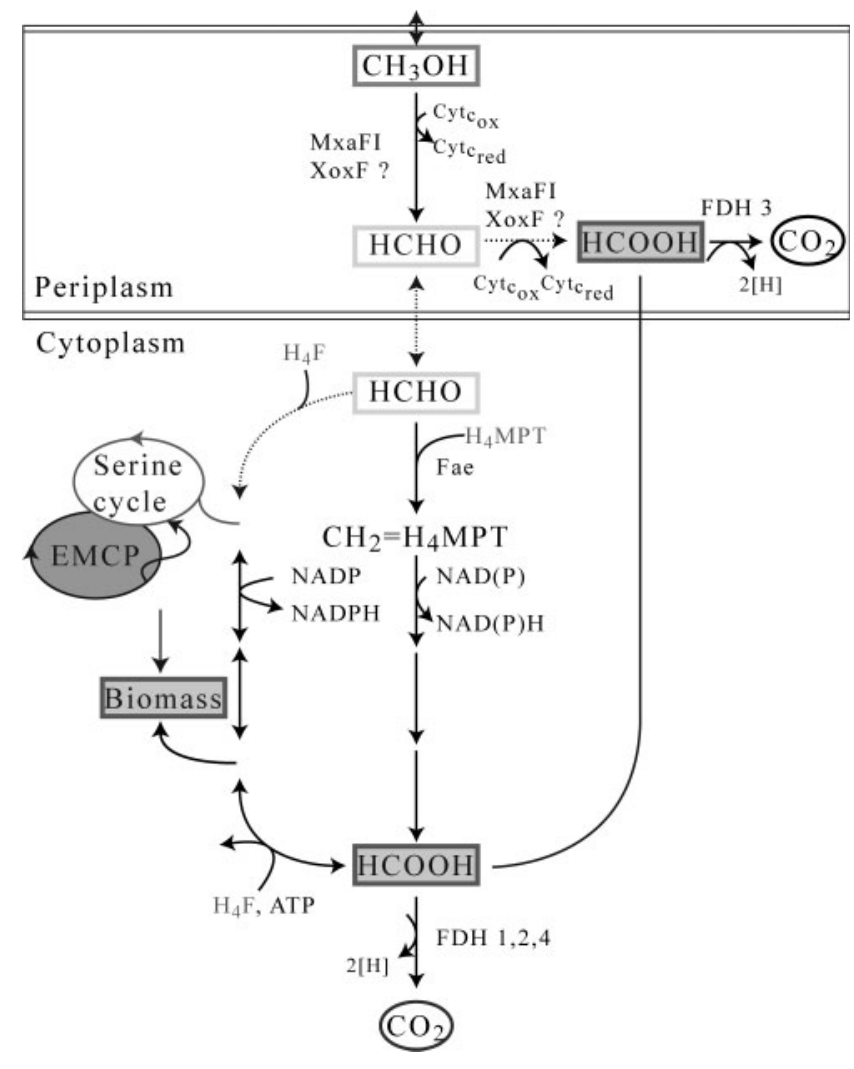

Fig. 1. Schematic view of one-carbon metabolism in $M$. extorquens, including XoxF. XoxF is suggested to be involved in periplasmic formaldehyde and/or methanol oxidation. Abbreviations: $\mathrm{Cyt}_{\mathrm{c}_{\mathrm{ox}}}$, oxidized cytochrome $\mathrm{c}$; $\mathrm{Cyt}_{\mathrm{c}_{\mathrm{red}}}$, reduced cytochrome c; $\mathrm{FDH}$, formate dehydrogenase; $\mathrm{H}_{4} \mathrm{~F}$, tetrahydrofolate; $\mathrm{H}_{4} \mathrm{MPT}$, tetrahydromethanopterin.

and additional genes for $\mathrm{Ca}^{2+}$ insertion (Anderson et al., 1990; Nunn et al., 1989; Springer et al., 1995). Previous research has demonstrated that a tetrahydromethanopterin $\left(\mathrm{H}_{4} \mathrm{MPT}\right)$-dependent pathway is essential for growth in the presence of methanol and is responsible for the oxidation of formaldehyde to formate in the cytoplasm (Chistoserdova et al., 1998; Pomper et al., 2002; Vorholt, 2002) (Fig. 1). Formate may either be oxidized to $\mathrm{CO}_{2}$ by formate dehydrogenases or converted via tetrahydrofolate $\left(\mathrm{H}_{4} \mathrm{~F}\right)$-dependent enzymes (Chistoserdova et al., 2004, 2007; Crowther et al., 2008). Methylene tetrahydrofolate is used for carbon assimilation via the serine cycle and the recently demonstrated ethylmalonyl-CoA pathway (Anthony, 1982; Chistoserdova et al., 2003; Erb et al., 2007; Peyraud et al., 2009). Other linear oxidation pathways exist in distinct methylotrophic bacteria, e.g. dependent on thiol compounds, as found in the autotrophic Alphaproteobacteria Paracoccus denitrificans and Rhodobacter sphaeroides (Barber et al., 1996; Barber \& Donohue, 1998; Ras et al., 1995).

The complete genome sequence of $M$. extorquens AM1 (Vuilleumier et al., 2009) revealed the presence of several genes encoding predicted paralogues of the large subunit of methanol dehydrogenase (MxaF), one of which is XoxF (ID ACS39584.1, META1_1740; Chistoserdova \& Lidstrom, 1997) of a predicted mass of $65 \mathrm{kDa}$. XoxF exhibits a sequence identity to $\mathrm{MxaF}$ of $50 \%$, possesses a predicted signal peptide for periplasmic localization, and conserved amino acid residues involved in PQQ and $\mathrm{Ca}^{2+}$ binding of methanol dehydrogenase (Anthony \& Williams, 2003) (Supplementary Fig. S1). A xoxF mutant is able to grow in the presence of methanol as the sole source of carbon and energy, and no obvious phenotype has been described (Chistoserdova \& Lidstrom, 1997). XoxF proteins form a distinct subgroup within the family of quinoprotein alcohol dehydrogenases (Chistoserdova et al., 2009; Kalyuzhnaya et al., 2008; Kane et al., 2007).

In addition to $M$. extorquens strains, other methylotrophic bacteria exhibit paralogues of methanol dehydrogenase, such as $P$. denitrificans. The presence of a $x o x F$ gene of $P$. denitrificans has been noted earlier. A reduced growth on methanol was observed for an insertion mutant in the neighbouring $c y c B$ gene, encoding a cytochrome $c_{553 \mathrm{i}}$ (Ras et al., 1991). The complete genome sequences of other bacteria indicate the presence of $x o x F$ but not of $m x a F$, such as R. sphaeroides (Wilson et al., 2008) and Methylibium petroleiphilum PM1 (Kane et al., 2007), and for other strains for which no methylotrophic growth has been fully established so far, e.g. Bradyrhizobium japonicum (Muhlencoert \& Müller, 2002; Sudtachat et al., 2009) and Beggiatoa alba (Jewell et al., 2008). Among the organisms possessing XoxF but not MxaF, the physiology of XoxF has been investigated in $R$. sphaeroides. The gene encoding XoxF has been shown to be essential for methanoldependent oxygen uptake and required for the utilization of methanol as the sole photosynthetic carbon source (Wilson et al., 2008). Recent environmental studies have documented the induction of $x o x F$ expression in Methylophaga strain DMS010 during growth on dimethylsulfide (Schäfer, 2007) and in Methylotenera mobilis during growth on methylamine (Bosch et al., 2009; Kalyuzhnaya et al., 2009), which points to its implication in one-carbon metabolism in these organisms.

XoxF was not detected in 2D protein gels when $M$. extorquens AM1 was grown on methanol minimal medium (Laukel et al., 2003), and has recently been shown to be present at about 100-fold lower amounts compared with MxaF using a liquid chromatograpy-MS/MS approach (Bosch et al., 2008). In contrast, XoxF was found to be highly expressed in bacterial phyllosphere communities in situ and was detected approximately as frequently as MxaF in shotgun proteomics (Delmotte et al., 2009). The identification of proteins during phyllosphere colonization of the strain $M$. extorquens PAl has confirmed the expression of xoxF (Mext_1809, corresponding to META1_1740; N. Delmotte and others, unpublished data). This observation suggests an important function of XoxF in a natural environment, i.e. the phyllosphere. In this study, we conducted a series of tests in order to search for a 
role for XoxF under in planta as well as under laboratory culture conditions. We demonstrate the importance of XoxF for plant colonization, the involvement of the enzyme in methanol/formaldehyde oxidation, and determine the molecular and catalytic properties of the purified enzyme.

\section{METHODS}

Bacterial constructs, cultures and growth conditions. The bacterial strains and plasmids used in this work are listed in Table 1. Escherichia coli DH5 $\alpha$ was grown on Luria-Bertani medium in the presence of antibiotics $\left(10 \mu \mathrm{g}\right.$ tetracycline $\mathrm{ml}^{-1}, 50 \mu \mathrm{g}$ kanamycin $\mathrm{ml}^{-1}$ ). Cultures of $M$. extorquens AM1 wild-type and xoxF insertion mutant (Chistoserdova \& Lidstrom, 1997) were grown on minimal media (Peyraud et al., 2009), supplemented with $0.5 \%$ $(\mathrm{v} / \mathrm{v})$ methanol or $0.5 \%(\mathrm{w} / \mathrm{v})$ succinate. Batch cultivations $(400 \mathrm{ml})$ were carried out in a $500 \mathrm{ml}$ bioreactor (Multifors, Infors-HT) at $28{ }^{\circ} \mathrm{C}$, at a stirring rate of 1000 r.p.m. and an aeration rate of 0.21 $\min ^{-1}$. The $\mathrm{pH}$ was maintained at 7.0 by addition of $1 \mathrm{M}$ ammonium hydroxide or $0.5 \mathrm{M}$ sulfuric acid. The partial pressure of dissolved oxygen (DO) was monitored using polarographic oxygen sensors (InPro 6800, Mettler-Toledo). Methanol concentrations were determined by GC-flame ionization detection (GC-FID) (GC 6850, Agilent Technologies; column: DB-Wax, J\&W Scientific) measurements, and
$\mathrm{CO}_{2}$ concentrations were monitored in the gas phase using an infrared sensor (BCP-CO $\mathrm{CO}_{2}$, BlueSens). In case of the $x \circ \mathrm{F} F$ mutant strain overexpressing $x o x F G J(\mathrm{pCM} 80-x o x F G J)$ and the $x o x F$ mutant with the empty pCM 80 vector, the minimal media were supplemented with a 10 -fold increased cobalt concentration $(12.6 \mu \mathrm{M}$ final concentration) to recover growth in the presence of the pCM80 plasmid and tetracycline (Kiefer et al., 2009). $\Delta m x a F /$ pCM80-xoxFhis was grown on minimal media with $30 \mathrm{mM}$ pyruvate. Antibiotics were used at the following concentrations: $10 \mu \mathrm{g}$ tetracycline $\mathrm{ml}^{-1}$, $50 \mu \mathrm{g}$ kanamycin $\mathrm{ml}^{-1}$ and $50 \mu \mathrm{g}$ rifamycin $\mathrm{ml}^{-1}$. The growth characteristicss of mutants were tested on plates containing 10 and $120 \mathrm{mM}$ methanol, 20 and $40 \mathrm{mM}$ pyruvate, $30 \mathrm{mM}$ succinate, $\mathrm{NH}_{4} \mathrm{Cl}\left(1.62 \mathrm{~g} \mathrm{l}^{-1}\right)$ or $\mathrm{KNO}_{3}\left(3.06 \mathrm{~g} \mathrm{l}^{-1}\right)$, or none or $1 \mathrm{mM}$ yeast nitrogen base without amino acids and ammonium sulfate (Difco, Chemie Brunschwig).

Construction of overexpressing strains, and oligonucleotides. For purification of XoxF from M. extorquens AM1, the xoxF gene was amplified His-tagged (C-terminal) with specific restriction sites $(X b a \mathrm{I}, E c o \mathrm{RI})$ and cloned into XbaI-EcoRI sites of the pCM80 expression vector (Marx \& Lidstrom, 2001). The overexpression vector pCM80 contains the $\mathrm{P}_{\mathrm{mxaF}}$ promoter of $M$. extorquens AM1. Positive clones were selected by tetracycline resistance and the lac $Z$ reporter gene. The forward primer included the $X b a \mathrm{I}$ site (XoxF_forw, $5^{\prime}$-atatattctagaggataagacttgtcggaggaatcc- $3^{\prime}$ ) and started $24 \mathrm{bp}$ upstream of the start codon to include the Shine-Dalgarno sequence. The reverse oligonucleotide (XoxF_rev_his, 5' -tatatagaattcttagtggt-

Table 1. Bacterial strains and plasmids used in this study

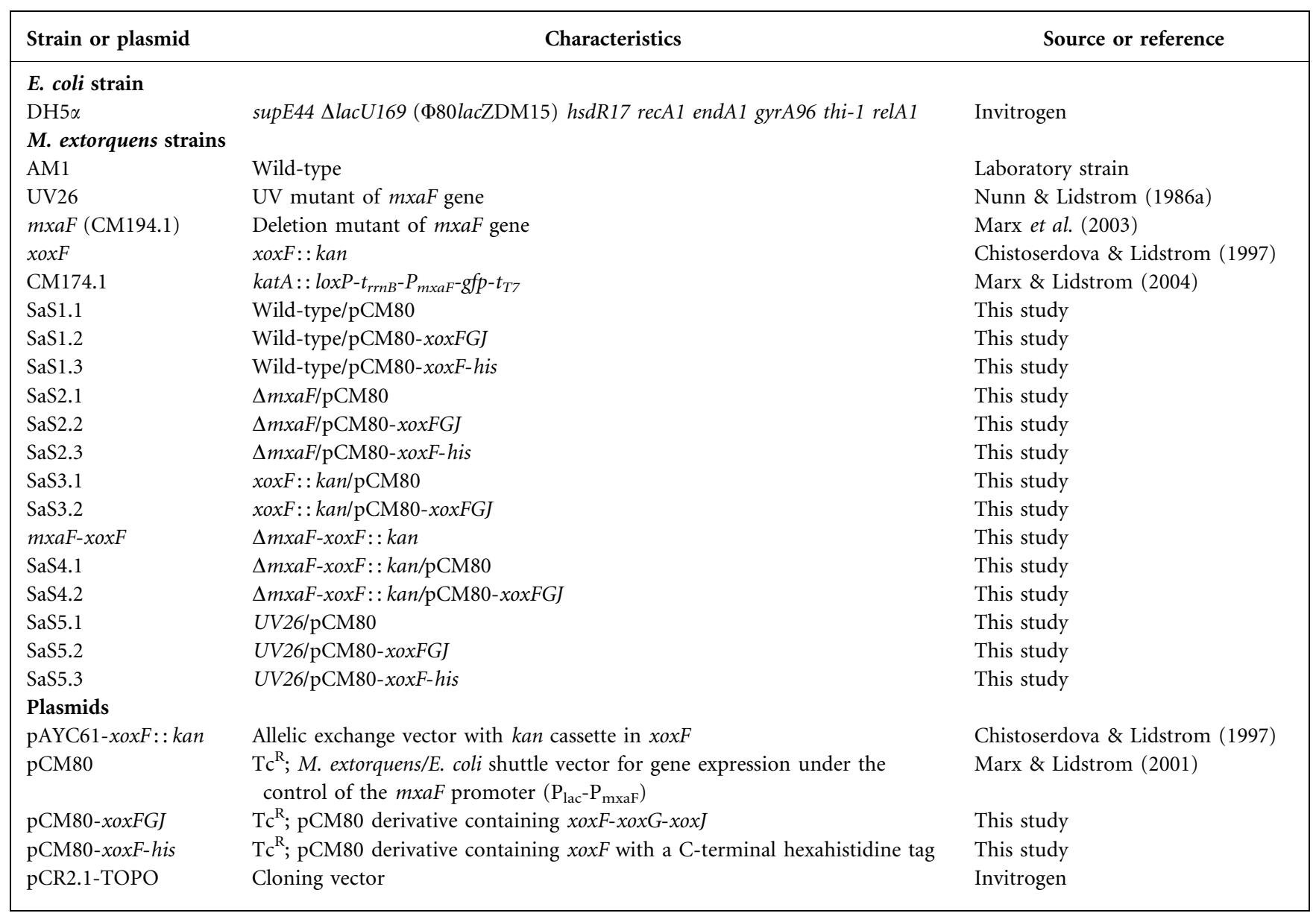


gatggtgatgatggttgttcggcagcgagaagaccg- $\left.3^{\prime}\right)$ contained the EcoRI site, the stop codon and the His-tag-coding sequence. The correct xoxF sequence was validated by sequencing. Finally, this plasmid, named pCM80-xoxF-his, was transformed into M. extorquens AM1 wild-type and $\triangle m x a F$.

The overexpression plasmid pCM80-xoxFGJ was created via $x o x F G J$ amplification using the forward oligonucleotide META1_1740forw1 $\left(5^{\prime}\right.$-aaatctagagctgccggagcgaatatcatcc- $\left.3^{\prime}\right)$ including an $\mathrm{XbaI}$ restriction site (primer start $100 \mathrm{bp}$ in front of the $x o x F$ start codon) and the reverse oligonucleotide META1_1742rev ( $5^{\prime}$-aaagaattcgggttcgggccttcgcatcacg- $3^{\prime}$ ) with an EcoRI site (oligonucleotide start 30 bp behind the stop codon). The three genes were first subcloned into the pCR2.1-TOPO vector (3.9 kb, Invitrogen). The ligation product was control-digested with $\mathrm{XbaI}, \mathrm{EcoRI}$ and $\mathrm{NcoI}$, and sequenced with the oligonucleotides M13forw (Invitrogen), META1_1740forw2 (5'aaatctagagcttgcgacatagagcctaaagg- $\left.3^{\prime}\right)$, META1_1740forw3 (5' -aaggtcatcgtcggcatctc- $\left.3^{\prime}\right)$, META1_1740forw4 (5' -agtactcgaccgagcagaac- $3^{\prime}$ ) and M13rev (Invitrogen). After verification of the correct sequence, xoxFGJ were cloned into pCM80. The $p C M 80-x o x F G J$ construct and the empty pCM 80 vector were transformed into $M$. extorquens AM1 wild-type, $\Delta m x a F$, UV26, $x o x F$ and $\Delta m x a F-x o x F$. The double mutant $\Delta m x a F-x o x F$ was created by means of the suicide vector pAYC61 (Chistoserdov et al., 1994) containing a $\mathrm{Km}^{\mathrm{R}}$ cassette flanked by $x o x F$ sequence parts with insertions at the sites for homologous recombination between the chromosome and the vector (Chistoserdova \& Lidstrom, 1997). The transformation into $\Delta m x a F$ was subjected to tetracycline selection and homologous recombination validated by kanamycin selection, followed by PCR amplification.

Seed sterilization, plant growth conditions and harvest. For plant inoculation experiments, $M$. extorquens cultures were grown in minimal medium with $30 \mathrm{mM}$ succinate. Exponentially grown cells were washed in $10 \mathrm{mM} \mathrm{MgCl}_{2}$, and $\mathrm{OD}_{600}$ was adjusted to $1.0\left(10^{8}\right.$ c.f.u. $\mathrm{ml}^{-1}$ ) for inoculation. Sterilized Arabidopsis thaliana ecotype Col-0 seeds were inoculated with a mixture $(5 \mu \mathrm{l})$ of GFP-labelled wild-type (CM174.1) and mutant strain (mxaF, xoxF or mxaF-xoxF). The competition of the GFP-labelled strain against the wild-type strain served as a control. The surface-sterilization of seeds was performed as described by Schlesier et al. (2003). After sterilizing the seeds with $70 \%(\mathrm{v} / \mathrm{v})$ ethanol $(2 \mathrm{~min})$ and a sodium hypochlorite solution (7\% chlorine) containing $0.2 \%(\mathrm{v} / \mathrm{v})$ Triton X-100 (8 min), seeds were washed seven times and thereafter incubated for $3 \mathrm{~h}$ in distilled water before the seeds were deposited. The bottoms of plant full-gas microboxes (Combiness) were filled with Murashige and Skoog media including vitamins (Duchefa), $3 \%(\mathrm{w} / \mathrm{v})$ sucrose and $0.55 \%(\mathrm{w} / \mathrm{v})$ plant agar (Murashige \& Skoog, 1962). Plants were harvested after 3 weeks of growth $\left(1\right.$ week at $22{ }^{\circ} \mathrm{C}, 16 \mathrm{~h} \mathrm{light} / 8 \mathrm{~h}$ darkness; 2 weeks at $22{ }^{\circ} \mathrm{C}, 9 \mathrm{~h}$ light/ $15 \mathrm{~h}$ darkness). The aerial parts of the plants were individually transferred to $2 \mathrm{ml}$ tubes containing $1 \mathrm{ml}$ phosphate buffer $(100 \mathrm{mM}, \mathrm{pH} 7.0)$. Bacteria were removed from the plant surfaces by shaking in a Retsch tissue lyser (15 min, $25 \mathrm{~Hz}$; Qiagen) and by ultrasonication ( $5 \mathrm{~min}$; Branson). Five- and 10 -fold dilution series of cell suspensions were plated onto minimal media (MM) with $30 \mathrm{mM}$ sodium succinate (5 days, $\left.28{ }^{\circ} \mathrm{C}\right)$. A fluorescence microscope (Zeiss Axioskop 2) was used to distinguish between colonies from GFP-labelled and unlabelled bacteria. All competition experiments with the M. extorquens AM1 GFP-labelled strain against the wild-type and mutant strains were repeated in three independent trials. The loss of competition for each strain mixture was calculated as the percentage of wild-type or mutant strain at day 0 (inoculum) minus the percentage of wild-type or mutant strain at day 21 (after 3 weeks of growth). An analysis of variance was performed to prove significant differences in the performance of the four tested strains based on post-hoc pairwise $t$ tests with Bonferroni correction.
All statistical analyses were done with the SYSTAT 12 statistical package.

M. extorquens cultures to perform starvation experiments
followed by addition of methanol/formaldehyde. $M$. extorquens $A M 1$, the $x o x F$ mutant, the $x o x F$ mutant strain overexpressing $x o x F G J$ (pCM80-xoxFGJ) and the $x o x F$ mutant with the empty pCM80 vector were grown to a final optical density of 9.5 in batch cultivation. To avoid growth inhibition, methanol was added stepwise during cultivation, maintaining its concentration below $0.5 \%$. Subsequently, cells were starved for $16 \mathrm{~h}$ and thereafter exposed to $60 \mathrm{mM}$ methanol or formaldehyde (methanol-free), added stepwise to a final concentration of $10 \mathrm{mM}$.

Before, during and after methanol/formaldehyde addition, samples $(1 \mathrm{ml})$ were taken from the cultures, filter-sterilized and used for formate analysis. At the beginning, a time- and concentrationdependent linear standard curve was established with sodium formate (Sigma-Aldrich). A volume of $0.01-0.2 \mathrm{ml}$ of filtrate (undiluted to 100 -fold diluted) was mixed with $50 \mathrm{mM}$ Tris/HCl buffer, $\mathrm{pH} 8.0$, $2 \mathrm{mM} \mathrm{NAD}^{+}$and yeast formate dehydrogenase (Sigma-Aldrich; $2 \mathrm{U}$ $\mathrm{ml}^{-1}$ ) in a total volume of $1 \mathrm{ml}$. After incubation $\left(60 \mathrm{~min}, 37^{\circ} \mathrm{C}\right.$ ), NADH was measured spectrophotometrically (Cary 50, Varian) in plastic cuvettes ( $1 \mathrm{~cm}$ path length) at $340 \mathrm{~nm}$ (Chistoserdova et al., 2007). All measurements were done in triplicate with $15 \%$ agreement.

A viability test was performed before and after starvation. To this end, three samples of the wild-type and mutant strain were taken before and after starvation. Cell dilutions were plated onto square plates with minimal media supplemented with methanol. The starvation of cells did not result in a significantly reduced viability of the bacterial cultures (SD $10 \%)$.

Purification of XoxF, determination of the molecular mass,
methanol dehydrogenase assay and enzyme kinetics. Pyruvategrown cells of $M$. extorquens AM1 $\Delta m x a F / p C M 80-x o x F-h i s ~(101$, $\left.\mathrm{OD}_{600} 1.0\right)$ and methanol-grown cells of $M$. extorquens AM1 wildtype/pCM80-xoxF-his (10 1, OD 4.0) were harvested by centrifugation at $16000 \mathrm{~g}$ using a Beckman Avanti J-26 XP centrifuge $\left(4{ }^{\circ} \mathrm{C}\right.$, $10 \mathrm{~min}$ ). Cells were resuspended in $25 \mathrm{mM} \mathrm{Tris} / \mathrm{HCl}, \mathrm{pH} \mathrm{8.0}$, $150 \mathrm{mM} \mathrm{NaCl}, 5 \mathrm{mM}$ imidazole, $\mathrm{pH} 8.0$, plus a protease inhibitor tablet (Complete, Roche) and passed through a French pressure cell (SLM Instruments) at $1.2 \times 10^{8} \mathrm{~Pa}$. Ultracentrifugation was performed at $200000 \mathrm{~g}$ for $1 \mathrm{~h}$ at $4{ }^{\circ} \mathrm{C}$ in a Kontron Centrikon T-1180 centrifuge to remove cell debris. The supernatant was loaded on an equilibrated $1 \mathrm{ml}$ HisTrap HP column (GE Healthcare). After a wash step with resuspension buffer containing $50 \mathrm{mM}$ imidazole, elution was performed with $400 \mathrm{mM}$ imidazole ( $1 \mathrm{ml}$ fractions). Fractions were analysed by $12.5 \%$ SDS-PAGE. Protein samples containing the desired protein were pooled, desalted and eluted from imidazole either via a PD-10 column (GE Healthcare) or by concentration (30 kDa Amicon Ultra centrifugal filter unit, Millipore) with buffer exchange (20 mM phosphate, $\mathrm{pH} 7.0$ ).

Purified XoxF was loaded onto a Superdex 200 (HiLoad 16/60) column (Amersham Pharmacia), equilibrated with $50 \mathrm{mM}$ Tris/HCl buffer, $\mathrm{pH} 8.0$, and $200 \mathrm{mM} \mathrm{NaCl}$ at a flow rate of $0.7 \mathrm{ml} \mathrm{min}{ }^{-1}$, using an ÄKTA purifier (Amersham Pharmacia). Apparent molecular masses were estimated by comparison with low and high molecular mass standards (Amersham Pharmacia).

Methanol dehydrogenase activity was measured using the method of Anthony \& Zatman (1967), with a modification using phenazine ethosulfate (PES)-mediated reduction (Ghosh \& Quayle, 1979) of 2,6dichlorophenol-indophenol [DCPIP; $\varepsilon_{600}=19.1 \mathrm{mM}^{-1} \mathrm{~cm}^{-1}$ (Basford \& Huennekens, 1955)]. The reaction was catalysed with the activator $\mathrm{NH}_{4} \mathrm{Cl}$ (final concentration $15 \mathrm{mM}$ ), which turned out to be essential for XoxF activity in this work. Assays were performed at room 
temperature in a total volume of $1 \mathrm{ml}$ in a quartz cuvette $(1 \mathrm{~cm}$ path length). One unit of specific enzyme activity was defined as one micromole DCPIP reduced per minute (determined at $600 \mathrm{~nm}$ ) and was expressed as units per milligram protein $\left(\mathrm{U} \mathrm{mg}^{-1}\right)$. For all spectrophotometric measurements, a Cary 50 (Varian) spectrophotometer was used.

In order to determine the $\mathrm{pH}$ optimum of XoxF in the dye-linked methanol dehydrogenase assay, potassium phosphate $(\mathrm{pH} 5.8-8.0$ ), Tris/HCl (pH 7.7-10.0) and MES buffers (5.5-6.5) were added, and XoxF was purified from $\Delta m x a F-p C M 80 x o x F-h i s$ cells grown on pyruvate.

Protein concentrations were quantified according to Bradford (1976) and by the bicinchoninic acid (BCA) test (Pierce) (Smith et al., 1985). Calibration curves were prepared using BSA as standard in $0.9 \% \mathrm{NaCl}$ (Sigma-Aldrich). The enzyme kinetics of XoxF were studied using the aforementioned assay conditions and varying substrate concentrations. The endogenous activity (in the absence of a carbon source) was subtracted from measured enzyme activities. Data were fitted with GraphPad Prism version 5.0 according to the Michaelis-Menten equation and Lineweaver and Burk. All alcohols, aldehydes and amines were purchased from Sigma-Aldrich.

\section{RESULTS}

\section{XoxF confers a growth advantage upon M. extorquens AM1 during colonization of A. thaliana under competitive conditions}

The expression of $x o x F$ during colonization of $A$. thaliana plants by $M$. extorquens under gnotobiotic conditions (N. Delmotte and others, unpublished data) and of the phyllosphere community (Delmotte et al., 2009) prompted our investigation into the importance of XoxF during plant colonization. The model plant $A$. thaliana has been used previously for inoculation experiments, and gnotobiotic conditions can be readily acquired (Gourion et al., 2006). A competitive approach was used because previous inoculation experiments of methylotrophy mutants have revealed a phenotype only when tested in competition with the wild-type strain (Sy et al., 2005). The difference between competitive and single inoculation set-ups might have been caused by the availability of alternative carbon sources, such as organic acids (Sy et al., 2005). To investigate the importance of XoxF, A. thaliana seeds were inoculated with a mixture of GFP-tagged wild-type strain (CM174.1), xoxF and mxaF mutants, and a mxaF-xoxF double mutant; the untagged wild-type served as control (Table 2). The plant inoculation experiments revealed that all these mutant strains were significantly less competitive than the wild-type $(P<0.001$, Table 2$)$. The relative decrease of the $x o x F$ mutant in competition was stronger than those of the other mutant strains $(P$ $<0.001)$; the mxaF mutant and the mxaF-xoxF double mutant showed similar losses. The data indicate the importance of XoxF for plant colonization under competitive conditions.
Table 2. Bacterial loss of competition (as a percentage) during plant colonization after 21 days

Seeds of $A$. thaliana were inoculated with $M$. extorquens wild-type, mxaF single mutant, $x o x F$ single mutant and mxaF-xoxF double mutant in competition with the GFP-labelled strain CM174.1. Results are based on the analysis of 72 plants per mixture combined from three independent trials.

\begin{tabular}{|lc|}
\hline $\begin{array}{c}\text { Strain in competition } \\
\text { with GFP-wild-type }\end{array}$ & $\begin{array}{c}\text { Loss of competition after 21 } \\
\text { days }(\%)\end{array}$ \\
\hline Wild-type & $3 \pm 1.3^{*}$ \\
$m x a F$ & $12 \pm 1.9$ \\
$x o x F$ & $23 \pm 1.7$ \\
$m x a F-x o x F$ & $13 \pm 1.5$ \\
\hline
\end{tabular}

${ }^{*}$ The $3 \%$ decrease of the wild-type in comparison with the GFPtagged strain after 21 days of plant growth was not significant (onesample $t$ test).

\section{The M. extorquens AM1 xoxF mutant shows a reduced growth rate during exponential growth}

A xoxF insertion mutant of $M$. extorquens AM1 has previously been described to be capable of growth in the presence of methanol as sole source of carbon and energy (Chistoserdova \& Lidstrom, 1997), and this was confirmed in this study. Although we noted no differences in growth rates for the $x o x F$ mutant relative to the wild-type during exponential growth on succinate (data not shown), in bioreactor experiments we found that the specific growth rate on methanol was reduced for the xoxF mutant by $30 \%$ relative to the wild-type (Table 3 ). This observation is the converse of the initial description of XoxF in M. extorquens AM1, where no difference in growth was noted (Chistoserdova \& Lidstrom, 1997). It is, however, similar to the findings described for the phenotype of a xoxG

Table 3. Cultivation parameters of $M$. extorquens AM1 wildtype and the xoxF mutant during exponential growth on methanol under the experimental conditions carried out in bioreactors

Methanol-specific yields and specific rates were determined from two biological replicates $(\mathrm{a}, \mathrm{b}) . \mu$, Growth rate; $\mathrm{Y}_{\mathrm{X} / \mathrm{S}}$, substrate-specific biomass yield; $\mathrm{Y}_{\mathrm{CO}_{2} / \mathrm{S}}$, substrate-specific $\mathrm{CO}_{2}$ yield; $\mathrm{q}_{\mathrm{S}}$, specific substrate uptake rate; $\mathrm{q}_{\mathrm{CO}_{2}}$, specific $\mathrm{CO}_{2}$ production rate.

\begin{tabular}{|lccccc|}
\hline \multirow{2}{*}{ Parameter } & \multicolumn{2}{c}{ Wild-type } & & \multicolumn{2}{c|}{ xoxF } \\
\cline { 2 - 3 } \cline { 5 - 6 } & $\mathbf{a}$ & $\mathbf{b}$ & & $\mathbf{a}$ & $\mathbf{b}$ \\
\hline$\mu\left(\mathrm{h}^{-1}\right)$ & 0.14 & 0.15 & & 0.10 & 0.10 \\
$\mathrm{Y}_{\mathrm{X} / \mathrm{S}}\left(\mathrm{g} \mathrm{g}^{-1}\right)$ & 0.21 & 0.20 & & 0.27 & 0.21 \\
$\mathrm{Y}_{\mathrm{CO}_{2} / \mathrm{s}}\left(\mathrm{g} \mathrm{g}^{-1}\right)$ & 0.45 & 0.36 & & 0.43 & 0.40 \\
$\mathrm{q}_{\mathrm{S}}\left(\mathrm{mmol} \mathrm{g}^{-1} \mathrm{~h}^{-1}\right)$ & 20.5 & 21.3 & & 12.9 & 13.2 \\
$\mathrm{q}_{\mathrm{CO}_{2}}\left(\mathrm{mmol} \mathrm{g}^{-1} \mathrm{~h}^{-1}\right)$ & 9.1 & 9.4 & & 5.6 & 5.5 \\
\hline
\end{tabular}


(cycB) mutant in P. denitrificans (Harms et al., 1996; Ras et al., 1991). Similar to the reduced growth rate for the $M$. extorquens AM1 xoxF mutant, we observed a decrease in the specific methanol conversion and $\mathrm{CO}_{2}$ production rate relative to the wild-type (Table 3 ). Inversely, the $x o x F$ mutant showed a comparable biomass yield (Table 3 ), suggesting that the amount of energy generated from methanol oxidation was unaltered.

Earlier results indicated that XoxF cannot functionally replace MxaF because a mxaF deletion mutant is not able to grow in the presence of methanol (Nunn \& Lidstrom, 1986a). In order to investigate whether the low expression level of $x o x F$ under laboratory conditions (Bosch et al., 2008) is responsible for the failure to substitute the true methanol dehydrogenase, we constructed strains expressing the $x o x F G J$ genes under the control of the mxaF promoter in $m x a F$ mutant backgrounds (deletion mutant and UV mutant, Table 1). The rationale for the expression of the xoxFGJ cluster, rather than xoxF alone, was based on the genome arrangement, which suggests that the gene products function together, and on observations made in the orthologous systems in $P$. denitrificans and $R$. sphaeroides (Chistoserdova \& Lidstrom, 1997; Ras et al., 1991; Wilson et al., 2008). No growth could be restored for these strains during tests under several conditions, such as various methanol concentrations, different nitrogen sources $\left(\mathrm{NH}_{4} \mathrm{Cl}, \mathrm{KNO}_{3}\right)$, and shifts from the multi-carbon substrates succinate and pyruvate to methanol with and without a period of carbon starvation.

\section{Consumption of methanol after carbon starvation indicates that XoxF is involved in efficient methanol oxidation}

The rate of methanol emission by plant leaves fluctuates depending on different parameters, such as stomatal conductance, stomata opening and leaf growth, and alternates in a diurnal manner (Fall \& Benson, 1996; Hüve et al., 2007). Because methylobacteria are subjected to changing concentrations of available carbon under environmental conditions and a generally limited supply of nutrients, we mimicked a sudden increase in methanol concentration after a phase of carbon starvation in a controlled bioreactor. We chose a relatively high final concentration of methanol $(60 \mathrm{mM})$ to enable us to monitor effects due to methanol oxidation more easily. The response of the $x o x F$ mutant was analysed in parallel to M. extorquens AM1 wild-type cells after starving cells for $16 \mathrm{~h}$ followed by the addition of methanol. Dissolved oxygen (DO) was measured to monitor substrate oxidation by the cultures. Since biomass concentrations and cultivation conditions were identical for both strains, DO is directly correlated with oxygen consumption, and differences in the latter can be directly monitored by DO. At regular time intervals, samples of the culture supernatant were taken and methanol concentration was determined using GC-FID. We observed very fast oxygen consumption as a response to methanol addition in the wild-type but not in the $\operatorname{xoxF}$ mutant (Fig. 2a). According to observed differences in oxygen consumption, the mutant strain required twice the time $(5 \mathrm{~h})$ to convert the methanol (Fig. 2a). This observation correlated with the measured methanol concentration in the medium (Fig. 2b). Similar results were observed when the $x o x F$ mutant strain overexpressing $x o x F G J$ (pCM80-xoxFGJ) and the $x o x F$ mutant with the empty pCM80 vector (control) were analysed after addition of methanol: methanol consumption occurred faster when $x o x F G J$ was expressed $(2.7 \mathrm{~h})$ relative to the mutant strain containing pCM80 (4.1 h) (Supplementary Fig. S2). Furthermore, we observed differences in the growth rates for $x o x F$ pCM80-xoxFGJ $\left(\mu=0.18 \mathrm{~h}^{-1}\right)$ and $x o x F$ pCM80 $\left(\mu=0.13 \mathrm{~h}^{-1}\right)$ of about $30 \%$. Interestingly, the growth rate found for the $x o x F$-overexpressing strain was significantly higher than the recently described growth rate of $M$. extorquens AM1 wild-type strain with the empty pCM80 plasmid grown under the same cultivation conditions ( $\mu=0.14 \mathrm{~h}^{-1}$; Kiefer et al., 2009).

\section{Carbon-starved $M$. extorquens AM1 wild-type, but not the xoxF mutant, accumulates formate during methanol and formaldehyde oxidation}

A $1 \mathrm{~h}$ lag phase in $\mathrm{CO}_{2}$ production occurred in the wildtype but not in the xoxF mutant (Fig. 2c), a result that might be indicative of an accumulation of formate after the addition of methanol to the wild-type. This observation prompted us to investigate the formate concentration in culture supernatants of the wild-type and the xoxF mutant. We found that the wild-type accumulated up to $14 \mathrm{mM}$ formate after starvation plus methanol addition, whereas the formate concentration in the $x o x F$ mutant did not rise beyond $400 \mu \mathrm{M}$ (Fig. 3a). This experiment suggests an additional capacity of the wild-type to form formate due to the expression of $x o x F$. In a subsequent experiment, we tested directly whether the oxidation of formaldehyde to formate was affected in the $x o x F$ mutant by adding formaldehyde instead of methanol to carbon-starved cells. To avoid poisoning the cells, we added $1 \mathrm{mM}$ formaldehyde 10 times over a time period of 0.5 and $1.3 \mathrm{~h}$ (wildtype and xoxF mutant, respectively). Wild-type cells converted the additional formaldehyde into formate stoichiometrically, whereas the xoxF mutant accumulated only up to one-fourth of the formate compared with the wild-type (Fig. 3b). The accumulation of formate in the medium after the addition of formaldehyde in the wildtype, but not in the xoxF mutant, indicates that XoxF is involved in formaldehyde oxidation or, alternatively, in the oxidation of methanol plus formaldehyde to formate.

Formate concentrations were also measured in supernatants of exponentially growing cells. Accumulation of only low amounts of formate (below $60 \mu \mathrm{M}$ ) during growth of $M$. extorquens AM1 in the presence of methanol has been demonstrated earlier (Chistoserdova et al., 2004, 2007). Here, we observed comparably low amounts of 
(a)

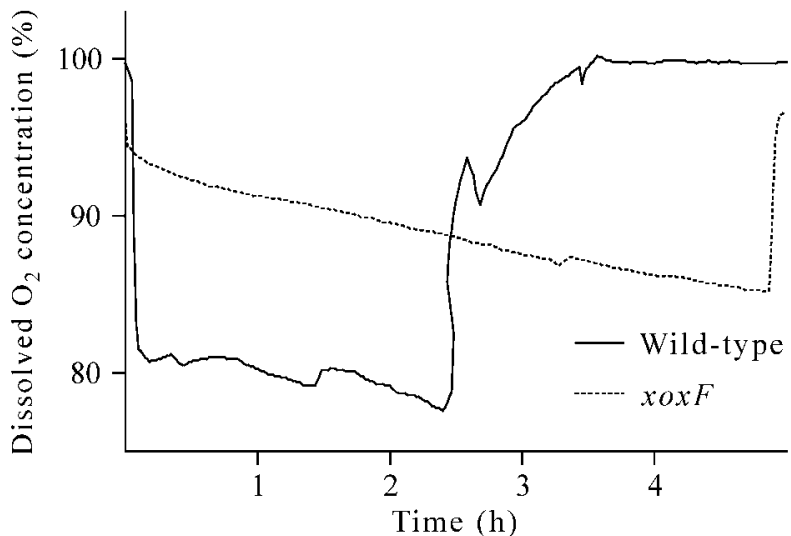

(b)

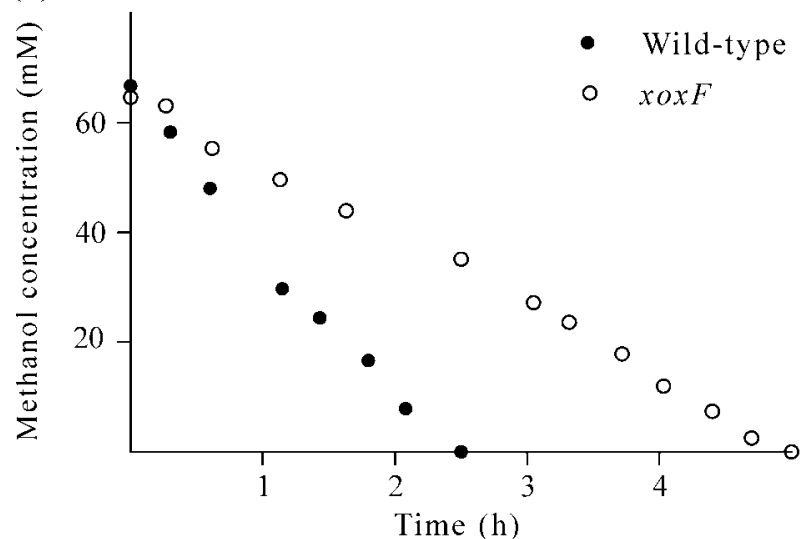

(c)

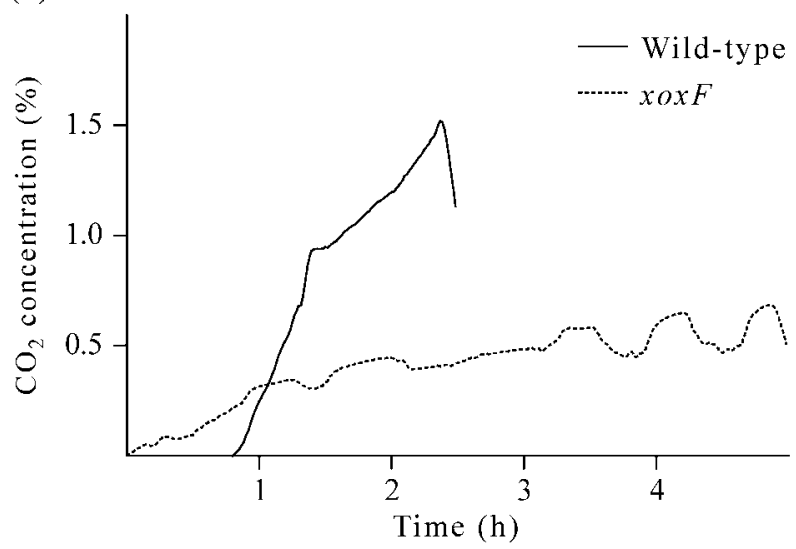

Fig. 2. Response of $M$. extorquens $A M 1$ wild-type (solid line/filled circles) and the $x o x F$ mutant (dotted line/open circles) upon addition of $0.25 \%(\mathrm{v} / \mathrm{v})$ methanol after carbon starvation $(16 \mathrm{~h})$ The monitored parameters were $\mathrm{DO}$ in the liquid phase (a), methanol concentration (b) and $\mathrm{CO}_{2}$ concentration in the exhausted gas phase (c). The experiment was confirmed twice with similar results and conducted at an optical density of 9.0 .

formate when the $x o x F$ mutant was analysed in parallel to the wild-type. Thus, the phenotype of the $x o x F$ mutant for one-carbon conversion to formate became evident only upon addition of a substrate after carbon starvation. (a)

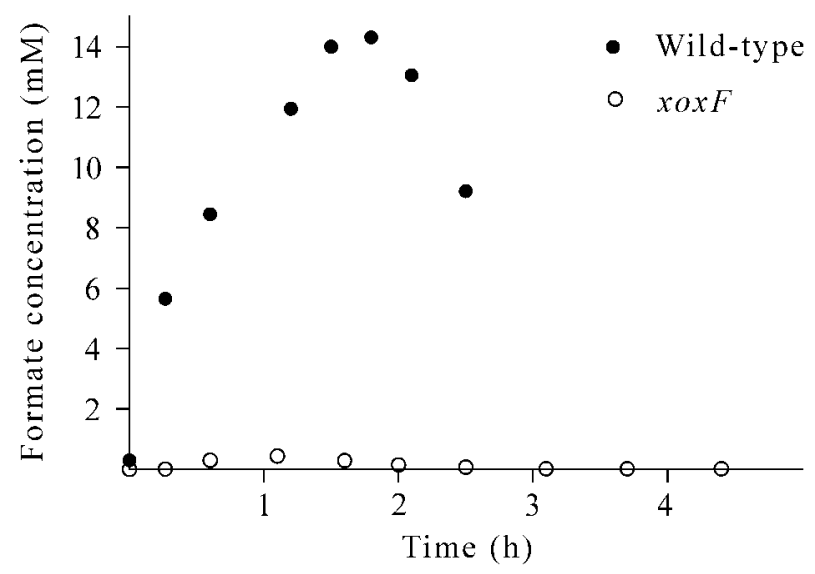

(b)

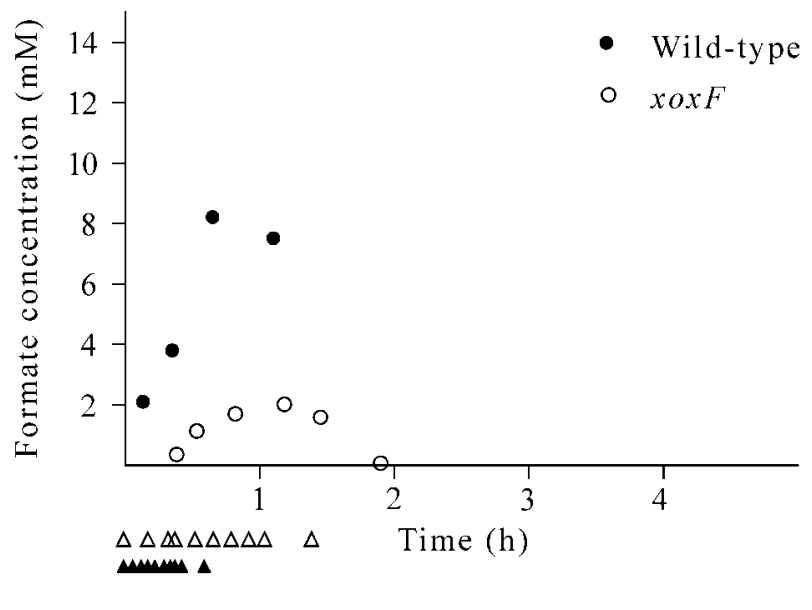

Fig. 3. Formate concentrations in culture supernatants of $M$. extorquens AM1 wild-type (filled circles) and the xoxF mutant (open circles) (a) upon addition of methanol (60 mM final concentration) and (b) upon addition of formaldehyde. The latter was supplemented stepwise to the wild-type (filled triangles) and $x o x F$ mutant (open triangles) up to a final concentration of $10 \mathrm{mM}$. The formate content of the supernatant was determined as described in Methods. The mean values of three biological replicates are indicated and all measurements agreed within $10 \%$.

\section{Purification of XoxF from M. extorquens AM1, determination of the apparent molecular mass, and substrate range}

To detect possible functions of XoxF, enzyme activities with crude extracts of $M$. extorquens AM1 wild-type cells and the $x o x F$ mutant were determined using the dye-linked methanol dehydrogenase assay. During the exponential growth phase, an enzyme activity of $0.2 \mathrm{U} \mathrm{mg}^{-1}$ was observed in crude extracts of the xoxF mutant, which was comparable with the wild-type. The activity was not increased when cells were taken after carbon starvation. Moreover, no methanol dehydrogenase activity was demonstrated in crude extracts of the mxaF deletion strain and the $\triangle m x a F / \mathrm{pCM} 80-x o x F G J$ strain. We therefore 
constructed a pCM80-xoxF-his vector for purification of XoxF via affinity chromatography from $M$. extorquens AM1. We used a $m x a F$ deletion background to exclude any contamination with methanol dehydrogenase and grew the cells on pyruvate. XoxF was purified to apparent homogeneity. The apparent molecular mass of the enzyme was determined to be $\sim 60 \mathrm{kDa}$ by gel filtration (Supplementary Fig. S3), indicating a monomeric structure of the native enzyme. The substrate ranges and substrate affinities of XoxF were investigated using a dye-linked PESdependent methanol dehydrogenase assay (Ghosh \& Quayle, 1979). The optimum $\mathrm{pH}$ for the oxidation of methanol was $\mathrm{pH}$ 9.0. The enzyme oxidized methanol, formaldehyde and ethanol with high affinity: the $K_{\mathrm{m}}$ for the carbon substrates were $11 \mu \mathrm{M}$ for methanol, $65 \mu \mathrm{M}$ for formaldehyde and $14 \mu \mathrm{M}$ for ethanol (Fig. 4). The $V_{\max }$ values were $0.015 \mathrm{U} \mathrm{mg}^{-1}$ for methanol, $0.014 \mathrm{U} \mathrm{mg}^{-1}$ for formaldehyde and $0.024 \mathrm{U} \mathrm{mg}^{-1}$ for ethanol. The indicated $K_{\mathrm{m}}$ and $V_{\max }$ values were calculated based on activities from which the endogenous activity of $0.01 \mathrm{U}$ $\mathrm{mg}^{-1}$ was subtracted [i.e. without substrate addition, also observed for purified methanol dehydrogenase MxaFI (Anthony \& Zatman, 1964; Anthony, 1986; Day \& Anthony, 1990; Duine et al., 1978; Duine \& Frank, 1980; Ghosh \& Quayle, 1981)]. In addition, other primary alcohols and aldehydes, including acetaldehyde, propionaldehyde, propan-1-ol, butan-1-ol and decan-1-ol, and the secondary alcohol propan-2-ol were converted by XoxF. However, the $K_{\mathrm{m}}$ values were in the millimolar range. Since the specific enzyme activities with methanol, formaldehyde and ethanol were lower than the ones determined for methanol dehydrogenase purified from methanol-grown cells $\left[V_{\max }\right.$ methanol dehydrogenase (MxaFI) 0.8-1.0 $\mathrm{U} \mathrm{mg}^{-1}$; Goodwin \& Anthony, 1996; Page \& Anthony, 1986], we also purified XoxF-his from methanol-grown cells using the wild-type containing pCM80-xoxF-his. Under these conditions, a slightly higher $V_{\max }$ value of $0.08 \mathrm{U} \mathrm{mg}^{-1}$ for XoxF was determined. An increased endogenous oxidation was observed, rendering accurate substrate affinity determination difficult. Ammonium was found to be essential for enzyme activity $\left(K_{\mathrm{a}}=8 \mathrm{mM}\right)$, similar to the observation made for methanol dehydrogenase in $M$. extorquens AM1 $\left(K_{\mathrm{a}}=2 \mathrm{mM}\right.$; Goodwin \& Anthony, 1996). Other amines, i.e. methylamine, dimethylamine, trimethylamine, ethylamine, n-butylamine, hexylamine, $\mathrm{n}$-heptylamine and $\mathrm{n}$-nonylamine, were tested as potential activators; however, they could not replace $\mathrm{NH}_{4} \mathrm{Cl}$ in the enzyme assays.

\section{DISCUSSION}

In this work, we investigated the role of $M$. extorquens XoxF in methanol and formaldehyde conversion. A possible function of XoxF in one-carbon metabolism of the organism has been previously considered, due to the $50 \%$ sequence identity to the large subunit of methanol dehydrogenase of the organism (Chistoserdova \&
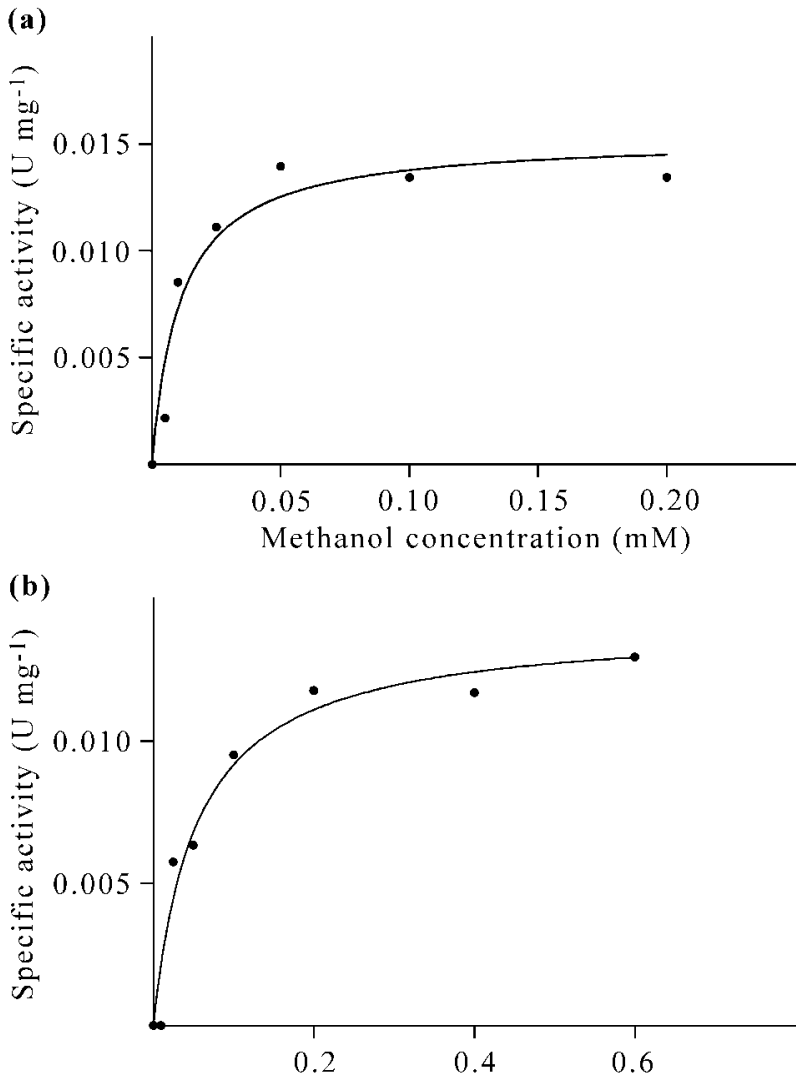

Formaldehyde concentration ( $\mathrm{mM}$ )

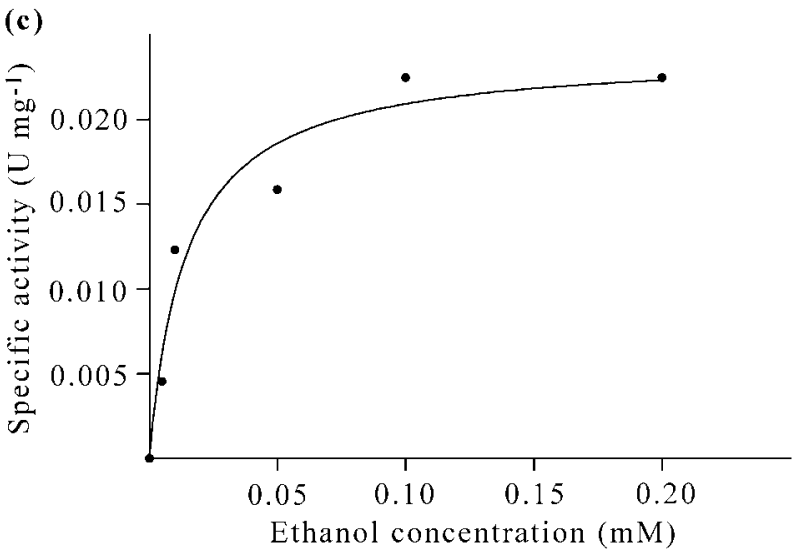

Fig. 4. Kinetics of purified XoxF. Specific XoxF activities $\left(\mathrm{U} \mathrm{mg}^{-1}\right)$ plotted against (a) methanol, (b) formaldehyde and (c) ethanol concentrations. To measure the activities, the PES/DCPIP-linked methanol dehydrogenase assay was applied. Endogenous activities of the enzyme (without substrate addition) were subtracted. Michaelis-Menten constants were determined by direct fitting of the curves to $K_{m}$ values and by double-reciprocal plots according to Lineweaver and Burk as a control.

Lidstrom, 1997) and the conservation of active site residues determined for the methanol dehydrogenase of the organism (Anthony \& Williams, 2003; Supplementary Fig. S1). However, no phenotype had been established 
earlier for the xoxF mutant from M. extorquens AM1. Here, we provide experimental evidence that XoxF of $M$. extorquens AM1 is involved in the one-carbon metabolism of the organism in addition to MxaF. Growth experiments revealed a $30 \%$ reduced specific methanol oxidation rate of a xoxF mutant (Table 3). This reduction is in agreement with the observed reduced growth rate during methylotrophic growth as opposed to that under non-methylotrophic conditions. Experiments involving carbon starvation followed by methanol addition also indicated that $\mathrm{XoxF}$ is required for efficient methanol oxidation because the $x o x F$ insertion mutant showed a reduced ability to convert methanol (Fig. 2a, b). The decrease in methanol oxidation might suggest an additional methanol oxidation capacity of XoxF. Such a role would suggest that a functional redundancy of MxaF and XoxF exists. However, a mxaF mutant is unable to grow in the presence of methanol (Nunn \& Lidstrom, 1986a), and we were unable to compensate the methanol growth defect of the mxaF mutant by overexpressing xoxFGJ. Although we cannot exclude that the failure to restore growth on methanol might be attributed to a coregulation of both enzymes through shared cofactors or other enzymes, these results suggest non-redundant functions of XoxF and MxaF.

An alternative enzyme activity of XoxF could be a primary role in formaldehyde oxidation. Notably, methanol dehydrogenase of $M$. extorquens AM1 catalyses not only the oxidation of methanol but also that of formaldehyde (Anthony \& Zatman, 1965). However, the significance of the latter activity in vivo is currently unclear. Interestingly, a so-called Modifier protein (M-protein) has been described that prevents the oxidation of formaldehyde by methanol dehydrogenase by lowering its affinity for formaldehyde (Bolbot \& Anthony, 1980; Ford et al., 1985; Page \& Anthony, 1986). It is thus tempting to speculate that the homotrimeric or tetrameric $45 \mathrm{kDa}$ subunit Modifier protein (Long \& Anthony, 1990, 1991) does not have the same effect on the methanol dehydrogenase-like protein XoxF, resulting in formaldehyde oxidation by XoxF in vivo. If XoxF acted as a bifunctional enzyme or was more specifically involved in periplasmic formaldehyde oxidation, it would represent an alternative route to the cytoplasmatic formation of formate via the tetrahydromethanopterin-dependent formaldehyde oxidation pathway, which includes formaldehyde-activating enzyme (Vorholt et al., 2000), methylene tetrahydromethanopterin dehydrogenase (Hagemeier et al., 2000), methenyl tetrahydromethanopterin cyclohydrolase (Pomper et al., 2002) and formyltransferase/hydrolase, which catalyses the transfer of the formyl group from tetrahydromethanopterin to a presumed methanofuran analogue and its subsequent hydrolysis to formate (Pomper \& Vorholt, 2001; Pomper et al., 2002) (Fig. 1). An indication for XoxF as a periplasmic formaldehyde dehydrogenase arises from the observed accumulation of formate after the addition of methanol or formaldehyde in the wild-type but not in the xoxF insertion mutant (Fig. 3). This result suggests an additional capacity of the wild-type to convert methanol plus formaldehyde or formaldehyde alone. Additional evidence is provided by the $1 \mathrm{~h}$ lag phase in $\mathrm{CO}_{2}$ production of the wild-type, which was not observed in the xoxF mutant (Fig. 2c). Because formate accumulation reached a maximum after $1.8 \mathrm{~h}$ under the experimental conditions, the additional capacity to oxidize formate to $\mathrm{CO}_{2}$ might have been induced after methanol addition. Multiple formate dehydrogenases have been previously identified (Chistoserdova et al., 2004, 2007). One of these formate dehydrogenases contains a Tat motif used for periplasmic localization (Palmer et al., 2005). A complete oxidation of methanol to $\mathrm{CO}_{2}$ in the periplasm of the cell might be envisioned under the situation of a sudden increase in the formaldehyde concentration (Fig. 1). During exponential growth, only very low amounts of formate accumulate in culture supernatants of $M$. extorquens AM1 wild-type cells (Chistoserdova et al., 2004) or the $x o x F$ mutant (this study), suggesting that formate oxidation is fast relative to its production. This equilibrium might become unbalanced when cells are starved for carbon and methanol is suddenly made available (Fig. 3). Under such conditions, additional oxidation capacity in the periplasm with concomitant reduction of a specific cytochrome for transfer of electrons to the terminal oxidase appears to be a plausible option for the role of XoxF as an additional formaldehyde-oxidizing enzyme.

In vitro enzyme assays using purified XoxF from $M$. extorquens AM1 revealed that the enzyme catalyses with highest affinity the oxidation of methanol, formaldehyde and ethanol, the three preferred substrates of methanol dehydrogenase $\left(K_{\mathrm{m}}\right.$ values of $10 \mu \mathrm{M}$ for methanol, formaldehyde and ethanol; Page \& Anthony, 1986). Similar also to methanol dehydrogenase, the $\mathrm{pH}$ optimum of XoxF was found to be 9.0 and the activity of XoxF in vitro was absolutely dependent on the presence of ammonium. The $V_{\max }$ value for XoxF of $0.08 \mathrm{U} \mathrm{mg}^{-1}$ (determined from methanol-grown cells, see Results) was 10 times smaller than those measured for methanol dehydrogenase (MxaFI) (0.8-1.0 U mg ${ }^{-1}$; Goodwin \& Anthony, 1996; Page \& Anthony, 1986). It should be noted that methanol dehydrogenase is composed of two different subunits, MxaF and MxaI, forming a heterotetrameric enzyme $\left(\alpha_{2} \beta_{2}\right)$ (Afolabi et al., 2001; Anthony \& Zatman, 1964; Williams et al., 2005), whereas XoxF is apparently a monomeric enzyme (Supplementary Fig. S3). An MxaIorthologous subunit is not encoded in the xox cluster. Because the subunit is also absent in the organisms lacking MxaF, such as R. sphaeroides, it had already been assumed that the enzyme functions without an additional subunit (Wilson et al., 2008). For this reason, it cannot be excluded that XoxF may be more fragile, resulting in the loss of specific activity during cell disruption and/or purification. No dye-linked XoxF activity could be detected in $R$. sphaeroides, and methanol activity was determined via oxygen consumption in intact cells (Wilson et al., 2008). A dye-linked alcohol dehydrogenase has been characterized, 
however, from another purple non-sulfur bacterium, Rhodopseudomonas acidophila, by Quayle's group (Bamforth \& Quayle, 1978, 1979; Sahm et al., 1976). Although the $65 \mathrm{kDa}$ protein (denaturing conditions) exhibits similarity to XoxF from $M$. extorquens AM1 regarding a wide substrate specificity range, the substrate affinities are completely different (e.g. $K_{\mathrm{m}}$ for ethanol $30 \mu \mathrm{M}, K_{\mathrm{m}}$ for methanol $120 \mathrm{mM}$ ) (Sahm et al., 1976). It is currently unclear whether the described dye-linked alcohol dehydrogenase from Rhodopseudomonas acidophila represents a XoxF orthologue.

Our results from the plant inoculation experiments indicate the importance of XoxF for plant colonization under competitive conditions (Table 2). The mxaF, xoxF and $m x a F-x o x F$ mutations resulted in a significant loss of competitive fitness, which was similar to earlier results that show that $M$. extorquens AM1 benefits from methanol dehydrogenase during colonization of Medicago truncatula (Sy et al., 2005). Here, we observed a significantly greater loss in the xoxF insertion strain when compared with the mxaF mutant in competition with the wild-type, pointing to a primary role for XoxF under environmental conditions. The high expression level of XoxF during the colonization of plants such as A. thaliana (Delmotte et al., 2009) may have effects that cannot currently be mimicked under 'in vivo' laboratory conditions. The higher expression level of XoxF under natural conditions may reveal additional phenotypes and the capacity to oxidize methanol, as well as formaldehyde, in the periplasm of the cell. This assumption is supported by the observed increase in growth rate of a strain expressing $x o x F G J$ under the control of the mxaF promoter (pCM80-xoxFGJ) relative to the wild-type with an empty plasmid.

We expect that the faster methanol conversion rate of the wild-type relative to the $x o x F$ mutant applies under natural conditions and is of physiological importance, given that the methanol emission rates of plants vary during the course of the day, such as upon the opening of stomata (Fall \& Benson, 1996). Under these environmental conditions, XoxF may help to capture the volatile plant product and consequently diminish its evaporation into the atmosphere. It may also prevent formaldehyde poisoning in the periplasm of the cell if a suddenly elevated amount of methanol becomes available. Additional investigation will be required to further elucidate the biochemical function of XoxF in methanol or formaldehyde oxidation. Furthermore, the molecular basis for the regulation of the expression level of XoxF remains to be uncovered.

\section{ACKNOWLEDGEMENTS}

We thank Ludmila Chistoserdova, Christopher J. Marx and Mary E. Lidstrom, University of Washington, Seattle (C. J. M. is now at Harvard University), for providing us with the mutant strains xoxF, UV26 and CM174.1, and Claudia Knief (ETH Zurich) for help in statistical analysis. This work was supported by ETH Zurich.

\section{REFERENCES}

Abanda-Nkpwatt, D., Musch, M., Tschiersch, J., Boettner, M. \& Schwab, W. (2006). Molecular interaction between Methylobacterium extorquens and seedlings: growth promotion, methanol consumption, and localization of the methanol emission site. J Exp Bot 57, 40254032.

Afolabi, P. R., Mohammed, F., Amaratunga, K., Majekodunmi, O., Dales, S. L., Gill, R., Thompson, D., Cooper, J. B., Wood, S. P. \& other authors (2001). Site-directed mutagenesis and X-ray crystallography of the PQQ-containing quinoprotein methanol dehydrogenase and its electron acceptor, cytochrome $c_{\mathrm{L}}$. Biochemistry 40, 9799-9809.

Anderson, D. J., Morris, C. J., Nunn, D. N., Anthony, C. \& Lidstrom, M. E. (1990). Nucleotide sequence of the Methylobacterium extorquens AM1 moxF and moxJ genes involved in methanol oxidation. Gene 90, 173-176.

Anthony, C. (1982). The Biochemistry of Methylotrophs. London: Academic Press.

Anthony, C. (1986). The bacterial oxidation of methane and methanol. Adv Microb Physiol 27, 113-210.

Anthony, C. \& Williams, P. (2003). The structure and mechanism of methanol dehydrogenase. Biochim Biophys Acta 1647, 18-23.

Anthony, C. \& Zatman, L. J. (1964). The methanol-oxidizing enzyme of Pseudomonas sp. M 27. Biochem J 92, 614-621.

Anthony, C. \& Zatman, L. J. (1965). The alcohol dehydrogenase of Pseudomonas sp. M27. Biochem J 96, 808-812.

Anthony, C. \& Zatman, L. J. (1967). The microbial oxidation of methanol: purification and properties of the alcohol dehydrogenase of Pseudomonas sp. M27. Biochem J 104, 953-959.

Bamforth, C. W. \& Quayle, J. R. (1978). The dye-linked alcohol dehydrogenase of Rhodopseudomonas acidophila. Comparison with dye-linked methanol dehydrogenases. Biochem J 169, 677-686.

Bamforth, C. W. \& Quayle, J. R. (1979). Structural aspects of the dyelinked alcohol-dehydrogenase of Rhodopseudomonas acidophila. Biochem J 181, 517-524.

Barber, R. D. \& Donohue, T. J. (1998). Function of a glutathionedependent formaldehyde dehydrogenase in Rhodobacter sphaeroides formaldehyde oxidation and assimilation. Biochemistry 37, 530-537.

Barber, R. D., Rott, M. A. \& Donohue, T. J. (1996). Characterization of a glutathione-dependent formaldehyde dehydrogenase from Rhodobacter sphaeroides. J Bacteriol 178, 1386-1393.

Basford, R. E. \& Huennekens, F. M. (1955). Studies on thiols. 1. Oxidation of thiol groups by 2,6-dichlorophenol indophenol. $J \mathrm{Am}$ Chem Soc 77, 3873-3877.

Bolbot, J. A. \& Anthony, C. (1980). The metabolism of 1,2propanediol by the facultative methylotroph Pseudomonas AM1. J Gen Microbiol 120, 245-254.

Bosch, G., Skovran, E., Xia, Q. W., Wang, T. S., Taub, F., Miller, J. A., Lidstrom, M. E. \& Hackett, M. (2008). Comprehensive proteomics of Methylobacterium extorquens AM1 metabolism under single carbon and nonmethylotrophic conditions. Proteomics 8, 3494-3505.

Bosch, G., Wang, T., Latypova, E., Kalyuzhnaya, M. G., Hackett, M. \& Chistoserdova, L. (2009). Insights into the physiology of Methylotenera mobilis as revealed by metagenome-based shotgun proteomic analysis. Microbiology 155, 1103-1110.

Bradford, M. M. (1976). A rapid and sensitive method for the quantitation of microgram quantities of protein utilizing the principle of protein-dye binding. Anal Biochem 72, 248-254.

Chistoserdov, A. Y., Chistoserdova, L. V., McIntire, W. S. \& Lidstrom, M. E. (1994). Genetic organization of the mau gene cluster in Methylobacterium extorquens AM1: complete nucleotide sequence and 
generation and characteristics of mau mutants. J Bacteriol 176, 40524065 .

Chistoserdova, L. \& Lidstrom, M. E. (1997). Molecular and mutational analysis of a DNA region separating two methylotrophy gene clusters in Methylobacterium extorquens AM1. Microbiology 143, 1729-1736.

Chistoserdova, L., Vorholt, J. A., Thauer, R. K. \& Lidstrom, M. E. (1998). C1 transfer enzymes and coenzymes linking methylotrophic bacteria and methanogenic Archaea. Science 281, 99-102.

Chistoserdova, L., Chen, S. W., Lapidus, A. \& Lidstrom, M. E. (2003). Methylotrophy in Methylobacterium extorquens AM1 from a genomic point of view. J Bacteriol 185, 2980-2987.

Chistoserdova, L., Laukel, M., Portais, J. C., Vorholt, J. A. \& Lidstrom, M. E. (2004). Multiple formate dehydrogenase enzymes in the facultative methylotroph Methylobacterium extorquens AM1 are dispensable for growth on methanol. J Bacteriol 186, 22-28.

Chistoserdova, L., Crowther, G. J., Vorholt, J. A., Skovran, E., Portais, J. C. \& Lidstrom, M. E. (2007). Identification of a fourth formate dehydrogenase in Methylobacterium extorquens AM1 and confirmation of the essential role of formate oxidation in methylotrophy. J Bacteriol 189, 9076-9081.

Chistoserdova, L., Kalyuzhnaya, M. G. \& Lidstrom, M. E. (2009). The expanding world of methylotrophic metabolism. Annu Rev Microbiol 63, 477-499.

Corpe, W. A. \& Rheem, S. (1989). Ecology of the methylotrophic bacteria on living leaf surfaces. FEMS Microbiol Ecol 62, 243-250.

Crowther, G. J., Kosály, G. \& Lidstrom, M. E. (2008). Formate as the main branch point for methylotrophic metabolism in Methylobacterium extorquens AM1. J Bacteriol 190, 5057-5062.

Day, D. J. \& Anthony, C. (1990). Methanol dehydrogenase from Methylobacterium extorquens AM1. Methods Enzymol 188, 210-216.

Delmotte, N., Knief, C., Chaffron, S., Innerebner, G., Roschitzki, B., Schlapbach, R., von Mering, C. \& Vorholt, J. A. (2009). Community proteogenomics reveals insights into the physiology of phyllosphere bacteria. Proc Natl Acad Sci U S A 106, 16428-16433.

Duine, J. A. \& Frank, J., Jr (1980). Studies on methanol dehydrogenase from Hyphomicrobium X. Isolation of an oxidized form of the enzyme. Biochem J 187, 213-219.

Duine, J. A., Frank, J. \& Westerling, J. (1978). Purification and properties of methanol dehydrogenase from Hyphomicrobium X. Biochim Biophys Acta 524, 277-287.

Erb, T. J., Berg, I. A., Brecht, V., Muller, M., Fuchs, G. \& Alber, B. E. (2007). Synthesis of C-5-dicarboxylic acids from C-2-units involving crotonyl-CoA carboxylase/reductase: the ethylmalonyl-CoA pathway. Proc Natl Acad Sci U S A 104, 10631-10636.

Fall, R. \& Benson, A. A. (1996). Leaf methanol - the simplest natural product from plants. Trends Plant Sci 1, 296-301.

Ford, S., Page, M. D. \& Anthony, C. (1985). The role of a methanol dehydrogenase modifier protein and aldehyde dehydrogenase in the growth of Pseudomonas AM1 on 1,2-propanediol. J Gen Microbiol 131, 2173-2182.

Ghosh, R. \& Quayle, J. R. (1979). Phenazine ethosulfate as a preferred electron-acceptor to phenazine methosulfate in dye-linked enzyme assays. Anal Biochem 99, 112-117.

Ghosh, R. \& Quayle, J. R. (1981). Purification and properties of the methanol dehydrogenase from Methylophilus methylotrophus. Biochem J 199, 245-250.

Goodwin, M. G. \& Anthony, C. (1996). Characterization of a novel methanol dehydrogenase containing a $\mathrm{Ba}^{2+}$ ion at the active site. Biochem J 318, 673-679.
Gourion, B., Rossignol, M. \& Vorholt, J. A. (2006). A proteomic study of Methylobacterium extorquens reveals a response regulator essential for epiphytic growth. Proc Natl Acad Sci U S A 103, 13186-13191.

Hagemeier, C. H., Chistoserdova, L., Lidstrom, M. E., Thauer, R. K. \& Vorholt, J. A. (2000). Characterization of a second methylene tetrahydromethanopterin dehydrogenase from Methylobacterium extorquens AM1. Eur J Biochem 267, 3762-3769.

Harms, N., Ras, J., Koning, S., Reijnders, W. N. M., Stouthamer, A. H. \& Van Spanning, R. J. M. (1996). Genetics of $C_{1}$ metabolism regulation in Paracoccus denitrificans. In Microbial Growth on $C_{1}$ Compounds, pp. 126-132. Edited by M. E. Lidstrom \& F. R. Tabita. Dordrecht: Kluwer Academic Publishers.

Hirano, S. S. \& Upper, C. D. (1991). Bacterial community dynamics. In Microbial Ecology on Leaves, pp. 271-294. Edited by J. H. Andrews \& S. S. Hirano. New York: Springer-Verlag.

Hüve, K., Christ, M. M., Kleist, E., Uerlings, R., Niinemets, U., Walter, A. \& Wildt, J. (2007). Simultaneous growth and emission measurements demonstrate an interactive control of methanol release by leaf expansion and stomata. J Exp Bot 58, 1783-1793.

Jewell, T., Huston, S. L. \& Nelson, D. C. (2008). Methylotrophy in freshwater Beggiatoa alba strains. Appl Environ Microbiol 74, 55755578.

Kalyuzhnaya, M. G., Hristova, K. R., Lidstrom, M. E. \& Chistoserdova, L. (2008). Characterization of a novel methanol dehydrogenase in representatives of Burkholderiales: implications for environmental detection of methylotrophy and evidence for convergent evolution. J Bacteriol 190, 3817-3823.

Kalyuzhnaya, M. G., Martens-Habbena, W., Wang, T., Hackett, M., Stolyar, S. M., Stahl, D. A., Lidstrom, M. E. \& Chistoserdova, L. (2009). Methylophilaceae link methanol oxidation to denitrification in freshwater lake sediment as suggested by stable isotope probing and pure culture analysis. Environ Microbiol Rep 1, 385-392.

Kane, S. R., Chakicherla, A. Y., Chain, P. S. G., Schmidt, R., Shin, M. W., Legler, T. C., Scow, K. M., Larimer, F. W., Lucas, S. M. \& other authors (2007). Whole-genome analysis of the methyl tert-butyl ether-degrading beta-proteobacterium Methylibium petroleiphilum PM1. J Bacteriol 189, 1931-1945.

Kiefer, P., Buchhaupt, M., Christen, P., Kaup, B., Schrader, J. \& Vorholt, J. A. (2009). Metabolite profiling uncovers plasmid-induced cobalt limitation under methylotrophic growth conditions. PLoS One 4, e7831.

Knief, C., Frances, L., Cantet, F. \& Vorholt, J. A. (2008). Cultivationindependent characterization of Methylobacterium populations in the plant phyllosphere by automated ribosomal intergenic spacer analysis. Appl Environ Microbiol 74, 2218-2228.

Knief, C., Ramette, A., Frances, L., Alonso-Blanco, C. \& Vorholt, J. A. (2010). Site and plant species are important determinants of the Methylobacterium community composition in the plant phyllosphere. ISME J 4, 719-728.

Laukel, M., Chistoserdova, L., Lidstrom, M. E. \& Vorholt, J. A. (2003). The tungsten-containing formate dehydrogenase from Methylobacterium extorquens AM1: purification and properties. Eur J Biochem 270, 325-333.

Long, A. R. \& Anthony, C. (1990). Modifier protein for methanol dehydrogenase of methylotrophs. Methods Enzymol 188, 216-222.

Long, A. R. \& Anthony, C. (1991). The periplasmic modifier protein for methanol dehydrogenase in the methylotrophs Methylophilus methylotrophus and Paracoccus denitrificans. J Gen Microbiol 137, 2353-2360.

Madhaiyan, M., Poonguzhali, S., Kwon, S. W. \& Sa, T. M. (2009). Methylobacterium phyllosphaerae sp. nov., a pink-pigmented, facultat- 
ive methylotroph from the phyllosphere of rice. Int J Syst Evol Microbiol 59, 22-27.

Marx, C. J. \& Lidstrom, M. E. (2001). Development of improved versatile broad-host-range vectors for use in methylotrophs and other Gram-negative bacteria. Microbiology 147, 2065-2075.

Marx, C. J. \& Lidstrom, M. E. (2004). Development of an insertional expression vector system for Methylobacterium extorquens AM1 and generation of null mutants lacking $m t d A$ and/or $f c h$. Microbiology 150, 9-19.

Marx, C. J., Chistoserdova, L. \& Lidstrom, M. E. (2003). Formaldehyde-detoxifying role of the tetrahydromethanopterinlinked pathway in Methylobacterium extorquens AM1. J Bacteriol 185, 7160-7168.

Muhlencoert, E. \& Müller, P. (2002). A novel two-component system of Bradyrhizobium japonicum: ElmS and ElmR are encoded in diverse orientations. DNA Seq 13, 93-102.

Murashige, T. \& Skoog, F. (1962). A revised medium for rapid growth and bioassays with tobacco tissue cultures. Physiol Plant 15, 473-497.

Nunn, D. N. \& Lidstrom, M. E. (1986a). Isolation and complementation analysis of 10 methanol oxidation mutant classes and identification of the methanol dehydrogenase structural gene of Methylobacterium sp. strain AM1. J Bacteriol 166, 581-590.

Nunn, D. N. \& Lidstrom, M. E. (1986b). Phenotypic characterization of 10 methanol oxidation mutant classes in Methylobacterium sp. strain AM1. J Bacteriol 166, 591-597.

Nunn, D. N., Day, D. \& Anthony, C. (1989). The second subunit of methanol dehydrogenase of Methylobacterium extorquens AM1. Biochem J 260, 857-862.

Page, M. D. \& Anthony, C. (1986). Regulation of formaldehyde oxidation by the methanol dehydrogenase modifier proteins of Methylophilus methylotrophus and Pseudomonas AM1. J Gen Microbiol 132, 1553-1563.

Palmer, T., Sargent, F. \& Berks, B. C. (2005). Export of complex cofactor-containing proteins by the bacterial Tat pathway. Trends Microbiol 13, 175-180.

Peel, D. \& Quayle, J. R. (1961). Microbial growth on C1 compounds. 1. Isolation and characterization of Pseudomonas AM 1. Biochem J 81, 465-469.

Peyraud, R., Kiefer, P., Christen, P., Massou, S., Portais, J. C. \& Vorholt, J. A. (2009). Demonstration of the ethylmalonyl-CoA pathway by using ${ }^{13} \mathrm{C}$ metabolomics. Proc Natl Acad Sci U S A 106, 4846-4851.

Pomper, B. K. \& Vorholt, J. A. (2001). Characterization of the formyltransferase (Ftr) from Methylobacterium extorquens AM1. Eur J Biochem 268, 4769-4775.

Pomper, B. K., Saurel, O., Milon, A. \& Vorholt, J. A. (2002). Generation of formate by the formyltransferase/hydrolase complex (Fhc) from Methylobacterium extorquens AM1. FEBS Lett 523, 133-137.

Ras, J., Reijnders, W. N., Van Spanning, R. J., Harms, N., Oltmann, L. F. \& Stouthamer, A. H. (1991). Isolation, sequencing, and mutagenesis of the gene encoding cytochrome $c_{553 \mathrm{i}}$ of Paracoccus denitrificans and characterization of the mutant strain. J Bacteriol 173, 6971-6979.

Ras, J., Van Ophem, P. W., Reijnders, W. N., Van Spanning, R. J., Duine, J. A., Stouthamer, A. H. \& Harms, N. (1995). Isolation, sequencing, and mutagenesis of the gene encoding NAD- and glutathione-dependent formaldehyde dehydrogenase (GD-FALDH) from Paracoccus denitrificans, in which GD-FALDH is essential for methylotrophic growth. J Bacteriol 177, 247-251.

Sahm, H., Cox, R. B. \& Quayle, J. R. (1976). Metabolism of methanol by Rhodopseudomonas acidophila. J Gen Microbiol 94, 313-322.

Schäfer, H. (2007). Isolation of Methylophaga spp. from marine dimethylsulfide-degrading enrichment cultures and identification of polypeptides induced during growth on dimethylsulfide. Appl Environ Microbiol 73, 2580-2591.

Schlesier, B., Bréton, F. \& Mock, H. P. (2003). A hydroponic culture system for growing Arabidopsis thaliana plantlets under sterile conditions. Plant Mol Biol Rep 21, 449-456.

Schrader, J., Schilling, M., Holtmann, D., Sell, D., Filho, M. V., Marx, A. \& Vorholt, J. A. (2009). Methanol-based industrial biotechnology: current status and future perspectives of methylotrophic bacteria. Trends Biotechnol 27, 107-115.

Smith, P. K., Krohn, R. I., Hermanson, G. T., Mallia, A. K., Gartner, F. H., Provenzano, M. D., Fujimoto, E. K., Goeke, N. M., Olson, B. J. \& Klenk, D. C. (1985). Measurement of protein using bicinchoninic acid. Anal Biochem 150, 76-85.

Springer, A. L., Chou, H. H., Fan, W. H., Lee, E. \& Lidstrom, M. E. (1995). Methanol oxidation mutants in Methylobacterium extorquens AM1: identification of new genetic complementation groups. Microbiology 141, 2985-2993.

Sudtachat, N., Ito, N., Itakura, M., Masuda, S., Eda, S., Mitsui, H., Kawaharada, Y. \& Minamisawa, K. (2009). Aerobic vanillate degradation and C-1 compound metabolism in Bradyrhizobium japonicum. Appl Environ Microbiol 75, 5012-5017.

Sy, A., Timmers, A. C., Knief, C. \& Vorholt, J. A. (2005). Methylotrophic metabolism is advantageous for Methylobacterium extorquens during colonization of Medicago truncatula under competitive conditions. Appl Environ Microbiol 71, 7245-7252.

Vorholt, J. A. (2002). Cofactor-dependent pathways of formaldehyde oxidation in methylotrophic bacteria. Arch Microbiol 178, 239249.

Vorholt, J. A., Marx, C. J., Lidstrom, M. E. \& Thauer, R. K. (2000). Novel formaldehyde-activating enzyme in Methylobacterium extorquens AM1 required for growth on methanol. J Bacteriol 182, 66456650.

Vuilleumier, S., Chistoserdova, L., Lee, M. C., Bringel, F., Lajus, A., Zhou, Y., Gourion, B., Barbe, V., Chang, J. \& other authors (2009). Methylobacterium genome sequences: a reference blueprint to investigate microbial metabolism of $\mathrm{C} 1$ compounds from natural and industrial sources. PLoS One 4, e5584.

Williams, P. A., Coates, L., Mohammed, F., Gill, R., Erskine, P. T., Coker, A., Wood, S. P., Anthony, C. \& Cooper, J. B. (2005). The atomic resolution structure of methanol dehydrogenase from Methylobacterium extorquens. Acta Crystallogr D Biol Crystallogr 61, 75-79.

Wilson, S. M., Gleisten, M. P. \& Donohue, T. J. (2008). Identification of proteins involved in formaldehyde metabolism by Rhodobacter sphaeroides. Microbiology 154, 296-305.

Edited by: D. J. Arp 